\title{
Effects of Combined Profiles Derived from Sleep Quality and Disorders on Non-suicidal Self-injury (NSSI) Behaviors
}

\section{Uyku Kalitesi ve Bozukluklarından Elde Edilen Kombine Profillerin Intihar Dıșı Kendine Zarar Verme (NSSI) Davranıșları Üzerindeki Etkileri}

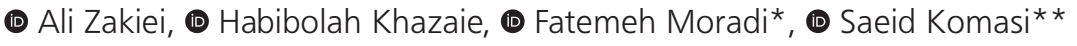 \\ Kermanshah University of Medical Sciences, Sleep Disorders Research Center, Kermanshah, Iran \\ ${ }^{*}$ Razi University Faculty of Medicine, Department of Psychology, Kermanshah, Iran \\ **Imam Reza Hospital, Kermanshah University of Medical Sciences, Clinical Research Development Center, Kermanshah, Iran
}

\begin{abstract}
Objective: The current study aims to evaluate the effects of combined profiles derived from sleep quality and disorders on non-suicidal selfinjury (NSSI).

Materials and Methods: The statistical population of this cross-sectional study included all the students at Razi University of Kermanshah City (Western Iran) during 2018. Among these students, 1104 participants (63.9\% female) of 18-35 years old were selected and responded to the questionnaires of the Pittsburgh Sleep Quality index, Insomnia Severity index, Berlin Questionnaire, and Inventory of Statements about Selfinjury.

Results: The results of the analysis show that the selected sample constitutes four clusters. There is a significant difference between the clusters with regards to NSSI. That is, these behaviors are more prevalent in the cluster with a higher number of sleep difficulties. On the other hand, the members of the healthy cluster have a more scarce history of such behaviors. The data were analyzed using the k-means cluster analyses and ANOVA.

Conclusion: Based on the results of the current study, it can be concluded that variables such as sleep quality, the intensity of insomnia, and sleep apnea play a significant role in the development of NSSI behaviors. In fact, sleep difficulties are a risk factor for NSSI behaviors. Keywords: Sleep quality, Sleep difficulties, Non-suicidal self-injury
\end{abstract}

Öz

Amaç: Uyku kalitesi ve bozukluklardan elde edilen kombine profillerin intihar amaçlı olmayan kendine zarar verme (NSSI) davranışları üzerindeki etkilerini değerlendirmek.

Gereç ve Yöntem: Bu kesitsel çalışmanın istatistiksel popülasyonu, 2018 yılı boyunca Kermanshah Şehri Razi Üniversitesi'ndeki (Batı İran) tüm öğrencileri içermektedir. Bu öğrencilerden 18-35 yaş arası 1104 katılımcı (\%63,9 kadın) seçildiler ve Pittsburgh Uyku Kalitesi indeksi, Uykusuzluk Şiddet indeksi, Berlin Anketi ve Kendini Yaralamayla Ilgili Beyan Envanteri'ne yanıt verdiler.

Bulgular: Analiz sonuçları, seçilen örneğin dört küme oluşturduğunu göstermektedir. NSSI açısından kümeler arasında önemli bir fark vardır. Yani bu davranışlar, daha fazla uyku güçlüğü olan kümede daha yaygındır. Öte yandan, sağlıklı kümenin üyeleri bu tür davranışların daha az öyküsüne sahiptir. Veriler, k-ortalamalar küme analizleri ve ANOVA kullanılarak analiz edildi.

Sonuç: Mevcut çalışmanın sonuçlarına göre uyku kalitesi, uykusuzluk yoğunluğu ve uyku apnesi gibi değişkenlerin NSSI davranışlarının gelişiminde önemli rol oynadığı sonucuna varılabilir. Aslında, uyku zorlukları NSSI davranışları için bir risk faktörüdür.

Anahtar Kelimeler: Uyku kalitesi, Uyku zorlukları, İntihar amaçlı olmayan kendine zarar verme

\section{Introduction}

Non-suicidal self-injury (NSSI) refers to self-inflicted behaviors which result in damages to a part or parts of the body. The person showing these behaviors is not trying to commit suicide (1). Various methods such as cutting, hitting, scratching, and burning the body are used for this purpose (2). In fact, NSSI involves behaviors that damage or disfigure a part of the body.
These behaviors are repetitive, voluntary, and direct, and they are not based on social norms and expectations. Of course, the goal of these behaviors is not suicide (3). There is a major difference between suicidal behavior and NSSI behaviors; NSSI involves damaging body tissue without a suicidal intent (4). It is argued that the prevalence of NSSI in general populations ranges from 5.5 to 17 percent. The prevalence rate of NSSI behaviors among teenagers is estimated to be 17.2 percent,

Address for Correspondence/Yazışma Adresi: Saeid Komasi MSc, Imam Reza Hospital, Kermanshah University of Medical Sciences, Clinical Research Development Center, Kermanshah, Iran Phone: +98 8334276299 E-mail: s_komasi63@yahoo.com ORCID-ID: orcid.org/0000-0002-0198-3710 Received/Geliş Tarihi: 11.02.2020 Accepted/Kabul Tarihi: 07.05.2020

${ }^{\circ}$ Copyright 2020 by Turkish Sleep Medicine Society / Journal of Turkish Sleep Medicine published by Galenos Publishing House. 
while it is estimated to be 13.4 percent among young adults, and 5.5 percent among adults (5).

The results of some studies show that NSSI is a risk factor for future suicide $(6,7)$. These behaviors can have adverse outcomes such as severe injury, hospitalization, or even death (8). Indeed, NSSI is one of the problems in the general health area (9). Therefore, it is essential to identify and evaluate its related factors.

The causes of NSSI can be divided into two main categories: personal factors (emotional dysregulation, mental disorders, and so on) and environmental factors (childhood abuse, attachment defects, and so on) (1). The results of a metaanalytic review show that people suffering from emotional disorders are more likely to engage in NSSI (10). The results of previous studies show that NSSI is associated with depression, anxiety, and post-traumatic stress disorder (11-13). In a recent study, factors such as being female, young age, higher education, childhood traumas, and mental disorders have been confirmed as risk factors for NSSI (14). Furthermore, reviewing previous studies shows that factors such as sexual abuse (15), negative life events (16), alexithymia (17), negative self-esteem (18), and personality disorders (19) are among NSSI risk factors. Nevertheless, one of the variables which can play a role in developing such behaviors is sleep difficulties. Sufficient sleep is essential for mental and physical health; in particular, sleep plays a significant role in emotion regulation, cognition, mental-social change, and physical growth (20). Problems such as insomnia, short sleep duration, sleep latency, and frequent waking up during nights are associated with NSSI behaviors (21). The results of another study show that people with sleep difficulties are more likely to engage in NSSI behaviors (22). However, there are some contradictory results in this area; the results of a study show that compared to healthy individuals, people with poor sleep quality don't show a significant difference in the likelihood of NSSI behaviors (23). In order to better understand the causes of NSSI as well as the effects of sleep on these behaviors, it is essential to carry out more studies. Therefore, the current study aims to investigate the effects of combined profiles derived from sleep quality, insomnia, and sleep apnea on NSSI.

\section{Materials and Methods}

\section{Design and Procedure}

The statistical population of this cross-sectional study included all the students in Razi University of Kermanshah City (Western Iran) during 2018. Among these students, 1200 participants were selected as the sample of the study. After collecting the questionnaires, 1104 participants (63.9\% female) of 18 to 35 years old were responded to the questionnaires of the Pittsburgh Sleep Quality index (PSQI), Insomnia Severity index (ISI), Berlin questionnaire, and Inventory of Statements about Self-injury (ISAS). Ninety-six people were eliminated from the sample due to lack of participation and/or ambiguous responses to the questionnaires. In order to follow ethical research protocols, the participants were assured that their responses would not be in any way provided to persons, public organizations, or private entities, and the completed questionnaires would only be utilized for research purposes. Then, the questionnaires were distributed among the participants, and they were informed that they could ask the researcher to clarify an issue if they encountered any problems with the questions. Ultimately, after collecting the questionnaires, the participants were thanked.

The inclusion criteria for the study included the following: (i) complete consent for participating in the study; (ii) the participants must be between 18 and 35 years old; (iii) the participants must be university students; and (iv) the participants mustn't have any chronic physical illnesses such as diabetes, cardiovascular diseases, pulmonary diseases, and thyroidal illnesses. The criteria for being eliminated from the study included the following: (i) being of a non-Iranian nationality; (ii) suffering from serious illnesses; (iii) suffering from chronic mental illnesses, particularly, personality disorders; and (iv) being addicted to any illicit drugs. Current mental disorder or drug addiction was evaluated using self-reports along with the semi-structured clinical form.

In order to follow ethical research procedures, the participants were informed that they could leave the study if they didn't want to participate for any reason. After expressing consent for participating in the study and obtaining necessary guarantees for the confidentiality of their information, the participants answered the questionnaires. It is worth mentioning that the current study is registered in Kermanshah University of Medical Sciences in Iran and it has obtained an ethical permit from the Ethical Committee of the University.

\section{Data Collection Tools}

The Pittsburgh Sleep Quality index: The Index is a self-report questionnaire developed by Buysse in 1989. This index is a standard questionnaire with 18 questions, with a total score ranging from 0 to 21 . The higher the total score is, the lower the sleep quality will be. Scores higher than 5 indicate poor sleep quality. The reliability of the PSQI was calculated using Cronbach's alpha coefficient, which was equal to 0.83 (24). In the current study, the Cronbach's alpha coefficient for this questionnaire was 0.91 .

The Insomnia Severity index: In order to measure the intensity of insomnia, the ISI, which includes 7 questions, was utilized. This index includes questions for evaluating the perceived severity of difficulties initiating sleep, staying asleep, early morning awakenings, satisfaction with current sleep pattern, interference with daily functioning, noticeability of impairment attributed to the sleep problem, and degree of distress or concern caused by the sleep problem. Each of these questions gets a score from 0 to 4 depending on the severity of the corresponding problem, and the final score for the individual is determined by adding the scores for these seven questions (25). In the current study, Cronbach's alpha coefficient for this questionnaire was 0.92 .

The Berlin questionnaire: This questionnaire is used for determining the risk of obstructive sleep apnea (OSA). The items in this questionnaire are divided into three sections of snoring (5 items), excessive sleepiness during daytime (3 items), 
and obesity and hypertension (2 items). This questionnaire has a total of 10 questions. Based on the results of this scale, we can identify individuals with a high risk of developing OSA (26). The results of a meta-analysis study show a high validity for this scale, and it can be used both for screening and for epidemiology (27).

Inventory of Statements about Self-injury: The ISAS that developed by Klonsky and Glenn (28) is a self-report tool for evaluating the frequency and functions of NSSI behaviors. This inventory has two sections. The first section of the ISAS assesses lifetime frequency of 12 NSSI behaviors performed intentionally (i.e., on purpose) and without suicidal intent. The behaviors assessed are banging/hitting self, biting, burning, carving, cutting, wound picking, needle-sticking, pinching, hair pulling, rubbing skin against rough surfaces, severe scratching, and swallowing chemicals. Moreover, the inventory also assesses some descriptive characteristics of NSSI behaviors. The reliability of the first section of the inventory based on the retest method in a time period of one to four weeks was reported as 0.85 (28). This questionnaire is scored based on a binary scale (i.e. 0 and $1)$; if the person has ever done a specific behavior, he/she will get a score of 1 ; otherwise, a score of 0 is given. In the current study, the Cronbach's alpha coefficient for the questionnaire is obtained as 0.82 .

\section{Statistical Analysis}

The data for continuous variables is reported in the form of mean and standard deviation, while the data for discrete variables are reported as values and percentages. In the cluster analysis, first, hierarchical agglomerative clustering (HAC) with squared Euclidean distance was used for identifying the number of clusters. In order to prevent the widespread impacts of fully-ordered multiple variables (sleep components) on each other, the centroid clustering method was used. Models with two to ten clusters were evaluated separately, indicating that the resolution of the 4-cluster model was better than other proposed models. At the next stage, the K-means clustering method was used for identifying the four clusters suggested by the original model. Ultimately, in order to evaluate the structural stability of the cluster solutions and to determine the consistency among the solutions, the Cramer's V test was used. Sleep components and mean scores for self-injury behaviors were compared among clusters using ANOVA. In order to compare the clusters with regards to nominal variables such as gender, the chi-square $X^{2}$ statistical test was used. All the statistical analyses were performed using SPSS 20 (IBM Corp., Armonk, NY, USA) software application. All the tests involved two ranges, and statistical significance was defined as $p$-value $<0.05$.

\section{Results}

The data analysis was performed for 1104 individuals, including 706 females (63.9\%) and 398 males (36.1\%), with an average age of $21.23 \pm 2.87$.

\section{Identified Clusters}

Table 1 presents the profile obtained from HAC and K-mean. The results of the Cramer's $V$ test $(0.37, p=0.0005)$ indicate that the structure of the cluster solutions in both models has good stability, and there is consistency between the solutions. This model suggested four clusters for sleep components, and as can be seen, there is a significant difference between the clusters $(p<0.001)$ with regards to all the components. the suggested clusters include the following: () the population with relatively poor sleep quality, low insomnia, and low sleep apnea; () the population with very poor sleep quality, very severe insomnia, and very high sleep apnea; () the population with good sleep quality, no insomnia, and no sleep apnea; and () the population with relatively poor sleep quality, severe insomnia, and relatively severe sleep apnea. As can be seen from Table 1, Cluster One includes 382 participants (36.1\%), Cluster Two includes 126 participants (9.2\%), Cluster Three includes 326 participants (30.3\%), and Cluster Four includes 270 participants (24.4\%).

\section{Sleep Profile of the Participants Based on Individual Clusters}

The results in Table 1 show that people in Cluster One have a poor sleep quality with a mean value of $5.98 \pm 2.09$, an insomnia level lower than the clinical threshold with a mean value of $9.94 \pm 5.86$, and low sleep apnea with a mean value of $1.08 \pm 1.20$; people in Cluster Two have a very poor sleep quality with a mean value of $7.09 \pm 3.48$, a high level of insomnia with a mean value of $21.18 \pm 2.57$, and a high level of sleep apnea with a mean value of $2.09 \pm 0.90$. In fact, with regards to sleep difficulties, the second cluster can be considered a clinical cluster. Moreover, the results show that people in Cluster Three have good sleep quality with a mean value of $4.87 \pm 2.10$, and they don't have any insomnia or sleep apnea problems; in other words, with regards to sleep profile, Cluster Three does not show any problems and it can be considered as the healthy group. The results show that people in Cluster Four have a poor quality of sleep with a mean value of $5.91 \pm 2.46$, with insomnia levels lower than the clinical threshold with a mean value of $15.10 \pm 1.50$, and relatively high levels of sleep apnea with a mean value of $1.53 \pm 1.26$. In fact, compared to Cluster

\begin{tabular}{|c|c|c|c|c|c|c|}
\hline Variable & Total $(n=1104)$ & $\begin{array}{l}\text { Cluster } 1 \\
(n=382 ; 36.1 \%)\end{array}$ & $\begin{array}{l}\text { Cluster } 2 \\
(n=126 ; 9.2 \%)\end{array}$ & $\begin{array}{l}\text { Cluster } 3 \\
(n=326 ; 30.3 \%)\end{array}$ & $\begin{array}{l}\text { Cluster } 4 \\
(n=270 ; 24.4 \%)\end{array}$ & p \\
\hline Sleep quality & $5.73 \pm 2.43$ & $5.98 \pm 2.09$ & $7.09 \pm 3.48$ & $4.87 \pm 2.10$ & $5.91 \pm 2.46$ & 0.001 \\
\hline Insomnia & $9.94 \pm 5.86$ & $8.98 \pm 1.70$ & $21.18 \pm 2.57$ & $3.49 \pm 1.90$ & $15.10 \pm 1.50$ & 0.001 \\
\hline Sleep apnea & $1.08 \pm 1.20$ & $0.99 \pm 1.09$ & $2.09 \pm 0.90$ & $0.50 \pm 0.99$ & $1.53 \pm 1.26$ & 0.001 \\
\hline Self-harm & $1.38 \pm 2.30$ & $1.20 \pm 1.98$ & $3.54 \pm 3.03$ & $0.52 \pm 1.17$ & $1.89 \pm 2.81$ & 0.001 \\
\hline
\end{tabular}


One, people in Cluster Four have a higher level of insomnia and sleep apnea.

\section{Demographic Characteristics of the Participants Based on Individual Clusters}

The results in Table 2 show that the average age of people in Cluster One is $21.08 \pm 2.82$, the average age of people in Cluster Two is $21.85 \pm 3.87$, the average age of people in Cluster Three is $21.26 \pm 3.01$, and the average age of people in Cluster Four is $21.20 \pm 2.28$. With regards to age, there is no significant difference between the clusters. Moreover, the results in Table 2 show that in Cluster One, $66.5 \%$ of the members are female while $33.5 \%$ of members are male; in Cluster Two, $79.4 \%$ of the members are female; in Cluster Three, $56.4 \%$ of the members are female; and in Cluster Four, $62.2 \%$ of the members are female. There is a significant difference between the clusters with regards to gender $(p<0.001)$. The results show that $9.4 \%$ of the members of Cluster One are married; $6.3 \%$ of the members of Cluster Two are married; $7.4 \%$ of the members of
Cluster Three are married; and $8.9 \%$ of the members of Cluster Four are married. However, there is no significant difference between the clusters with regards to marital status. The results also show that $3.1 \%$ of members of Cluster One smoke; $12.7 \%$ of the members of Cluster Two smoke; $5.5 \%$ of the members of Cluster Three smoke; and $11.1 \%$ of the members of Cluster Four smoke. That is, there is a significant difference between the clusters with regards to smoking $(p<0.001)$.

\section{Comparing NSSI Behaviors among Clusters}

The results presented in Table 1 show that the mean value of NSSI behaviors in cluster One was $1.20 \pm 1.98$; the mean value of NSSI behaviors in cluster Two was 3.54 3.03 ; the mean value of NSSI behaviors in cluster Three was $0.52 \pm 1.17$; and the mean value of NSSI behaviors in cluster Four was $1.89 \pm 2.81$. The results of One-Way analysis of variance (ANOVA) show that with regards to NSSI behaviors, there is a significant difference between the clusters $(F=50.41, p<0.001)$. In detail, people in Cluster Two had the highest frequency of NSSI behaviors, while

\begin{tabular}{|c|c|c|c|c|c|c|}
\hline Variable & Total $(n=1104)$ & $\begin{array}{l}\text { Cluster } 1 \\
(\mathrm{n}=382 ; 36.1 \%)\end{array}$ & $\begin{array}{l}\text { Cluster } 2 \\
(n=126 ; 9.2 \%)\end{array}$ & $\begin{array}{l}\text { Cluster } 3 \\
(n=326 ; 30.3 \%)\end{array}$ & $\begin{array}{l}\text { Cluster } 4 \\
(n=270 ; 24.4 \%)\end{array}$ & $p$ \\
\hline Age $(M \pm S D)$ & $21.23 \pm 2.87$ & $21.08 \pm 2.82$ & $21.85 \pm 3.87$ & $21.26 \pm 3.01$ & $21.20 \pm 2.28$ & 0.197 \\
\hline $\begin{array}{l}\text { Sex (\%) } \\
\text { Female } \\
\text { Male }\end{array}$ & $\begin{array}{l}706(63.9) \\
398(36.1)\end{array}$ & $\begin{array}{l}254(66.5) \\
128(33.5) \\
\end{array}$ & \begin{tabular}{|l}
$100(79.4)$ \\
$26(20.6)$ \\
\end{tabular} & $\begin{array}{l}184(56.4) \\
142(43.6)\end{array}$ & $\begin{array}{l}168(62.2) \\
102(37.8) \\
\end{array}$ & 0.001 \\
\hline Smoking (\%) & $76(6.9)$ & $12(3.1)$ & $16(12.7)$ & $18(5.5)$ & $30(11.1)$ & 0.001 \\
\hline
\end{tabular}

\begin{tabular}{|c|c|c|c|c|c|c|}
\hline Self-harm behavior (\%) & Total & Cluster 1 & Cluster 2 & Cluster 3 & Cluster 4 & $\mathrm{p}$ \\
\hline Amputation of the body organs & 11.6 & 10.5 & 31.8 & 6.9 & 15.5 & 0.001 \\
\hline Burning the body by cigarettes & 2.2 & 0 & 9.1 & 1.4 & 5.2 & 0.001 \\
\hline Body burner by light-box, match or other objects & 3.3 & 2.3 & 9.1 & 1.4 & 6.9 & 0.001 \\
\hline Engraving of letters on the skin of the body & 11.2 & 9.3 & 27.3 & 5.6 & 17.2 & 0.001 \\
\hline Engraving images and marks on the skin of the body & 13.4 & 9.3 & 36.4 & 8.3 & 17.2 & 0.001 \\
\hline Scratching the body until injured & 15.9 & 10.5 & 50 & 6.9 & 22.4 & 0.001 \\
\hline Biting body until injured & 6.5 & 10.5 & 18.2 & 0 & 5.2 & 0.001 \\
\hline Sandpapering on the body & 2.2 & 3.5 & 4.5 & 0 & 3.4 & 0.004 \\
\hline Spraying acid on the body & 1.4 & 1.2 & 4.5 & 2.8 & 5.2 & 0.001 \\
\hline Scratching the body with bleach & 2.9 & 4.7 & 4.5 & 0 & 3.4 & 0.004 \\
\hline Injecting sharp objects like nails in the body & 13 & 10.5 & 31.8 & 2.8 & 19 & 0.001 \\
\hline Wounding the body with glass & 4 & 3.5 & 13.6 & 1.4 & 3.4 & 0.001 \\
\hline Breaking bones & 1.8 & 1.2 & 4.5 & 0 & 5.2 & 0.001 \\
\hline Clinging head on hard objects & 17.8 & 14 & 45.5 & 11.1 & 17.2 & 0.001 \\
\hline Self-punching until contusion & 11.6 & 10.5 & 22.7 & 5.6 & 15.5 & 0.001 \\
\hline Prevent wound healing & 8.7 & 9.3 & 27.3 & 1.4 & 10.3 & 0.001 \\
\hline Other self-injurious behaviors & 9.4 & 10.5 & 18.2 & 1.4 & 13.8 & 0.001 \\
\hline
\end{tabular}


people in Cluster Three showed the lowest frequency for such behaviors; the mean value for NSSI behaviors in Cluster Four was higher than that of Cluster One. Comparing individual clusters using the Scheffe test showed a significant difference with regards to NSSI behaviors among all four clusters. As can be seen from Table 3, the highest frequency of individual NSSI behaviors is in Cluster Two, while the lowest frequency is seen in Cluster Three.

\section{Discussion}

In the current study, we clustered the participants based on variables of sleep quality, the intensity of insomnia, and sleep apnea. The results of the analysis show that based on these variables, four distinct clusters are created. These clusters included: Cluster One: the population with relatively poor sleep quality, low insomnia, and low sleep apnea; Cluster Two: the population with very poor sleep quality, very severe insomnia, and very high sleep apnea; Cluster Three: the population with good sleep quality, no insomnia, and no sleep apnea; and Cluster Four: the population with relatively poor sleep quality, severe insomnia, and relatively severe sleep apnea. Based on the nature of the selected tools, it can be said that considering sleep difficulties, Cluster Two can be considered a clinical cluster, while people in Cluster Three do not have any sleep profile problems and this cluster can be considered as the healthy cluster. The results of our study show that based on NSSI, there is a significant difference among the clusters; i.e. these behaviors were more frequency in Cluster Two which includes people with more severe sleep difficulties, while these behaviors were rare among the members of Cluster Three, which is considered the healthy cluster. In other words, people with higher levels of sleep difficulties are more likely to engage in NSSI behaviors.

The results of a previous study indicate that people with sleep problems report significantly higher numbers of NSSI behaviors. The results of that study confirmed that variables such as insomnia, short sleep duration, high latency in sleep initiation, waking after sleep onset, daytime naps, and sleep deficiency are all associated with NSSI behaviors (21). The results of another study on a sample of university students showed a positive association between insomnia and NSSI (29). The results of some other studies indicate the role of sleep difficulties and sleep quality in NSSI $(22,30)$. Therefore, the results of our study are in line with the findings of these studies. However, the results of some previous studies contradict our results. For instance, a study shows that variables such as sleep latency, REM latency, sleep efficiency, total sleep time, and apneahypopnea index are not related to NSSI behaviors (22).

In our study, the percentage of females in the second cluster, which showed a higher frequency of NSSI behaviors, was higher than 79 percent. Therefore, being female can be considered as a risk factor for NSSI. The results of another study indicate that there is a relationship between poor sleep quality and NSSI among females (31). The results of a longitudinal study show that 77 percent of the females who reported poor sleep quality at the first stage of the study, repeated NSSI behaviors within a year. This is while this issue is not reported among males. The results of that study indicate poor sleep quality as another risk factor for the development of NSSI behaviors among females (31), which is in line with the findings of our study.

In order to explain the results, we can mention the role of emotional dysregulation. In a study, the mediating role of emotional dysregulation in the relationship between nightmares (a sleep difficulty) and NSSI was evaluated. The results showed that emotional dysregulation played a mediating role in this relationship (29). One researcher claims that NSSI can be utilized as a maladaptive emotion regulation method for coping with negative emotions in children with a history of sexual abuse. The results of that study reported a relationship between insomnia and NSSI (32). As a general rule, it can be argued that poor sleep quality can increase emotional distress, which necessitates utilizing coping mechanisms, and NSSI acts as an emotional regulator $(8,33)$.

Our study was a cross-sectional one. Therefore, it is essential that future studies evaluate the effects of sleep variables on NSSI in a longitudinal fashion. On the other hand, trial studies can better investigate the impacts of such variables. Moreover, the measuring tools in our study were mainly self-report instruments, which is a serious issue for measuring behaviors such as sleep. Therefore, it is recommended that future studies utilize other instruments and measuring tools as well. Since the current study was performed in a City in Western Iran, when generalizing the results, caution must be exercised. Furthermore, these variables can be investigated in other populations.

\section{Conclusion}

Based on the results obtained in this study, it can be argued that variables such as sleep quality, the intensity of insomnia, and sleep apnea play a role in the development of NSSI behaviors. Indeed, sleep difficulties are a risk factor for NSSI. Furthermore, based on the findings of the current study, being female can be considered as a risk factor for such behaviors. Thus, in order to reduce the likelihood of NSSI, it is recommended to plan for improving sleep quality and mitigating sleep difficulties.

\section{Ethics}

Ethics Committee Approval: Kermanshah University of Medical Sciences in Iran and it has obtained an ethical permit from the Ethical Committee of the University. (ID: KUMS.REC.1396.56)

Informed Consent: Informed consent was obtained from all study participants.

Peer-review: Internally peer-review.

\section{Authorship Contributions}

Concept: A.Z., S.K., Design: A.Z., S.K., Data Collection or Processing: H.K., S.K., Analysis or Interpretation: A.Z., Literature Search: A.Z., H.K., , F.M. Writing: A.Z., H.K., S.K.

Conflict of Interest: No conflict of interest was declared by the authors.

Financial Disclosure: This study was supported by the Kermanshah University of Medical Sciences, Iran (ID: 96119). 


\section{References}

1. Cipriano A, Cella S, Cotrufo P. Nonsuicidal self-injury: A systematic review. Front Psychol 2017;8:1946.

2. Muehlenkamp JJ, Gutierrez PM. An investigation of differences between self-injurious behavior and suicide attempts in a sample of adolescents. Suicide Life Threat Behav 2004;34:12-23.

3. Association AP. Diagnostic and statistical manual of mental disorders (DSM-5尺): American Psychiatric Pub; 2013.

4. Nock MK, Prinstein MJ, Sterba SK. Revealing the form and function of self-injurious thoughts and behaviors: A real-time ecological assessment study among adolescents and young adults. J Abnorm Psychol 2009;118:816-27.

5. Swannell SV, Martin GE, Page A, Hasking P, St John NJ. Prevalence of nonsuicidal self-injury in nonclinical samples: Systematic review, meta-analysis and meta-regression. Suicide Life Threat Behav 2014;44:273-303.

6. Bryan C, Bryan A. Nonsuicidal self-injury among a sample of united states military personnel and veterans enrolled in college classes. J Clin Psychol 2014;70:874-85.

7. Whitlock J, Muehlenkamp J, Eckenrode J, Purington A, Abrams GB, Barreira P, Kress V. Nonsuicidal self-injury as a gateway to suicide in young adults. J Adolesc Health 2013;52:486-92.

8. Klonsky ED. The functions of self-injury in young adults who cut themselves: Clarifying the evidence for affect-regulation. Psychiatry Res 2009;166:260-8.

9. Mars B, Heron J, Crane C, Hawton K, Lewis G, Macleod J, Tilling K, Gunnell D. Clinical and social outcomes of adolescent self harm: population based birth cohort study. BMJ 2014;349:5954.

10. Bentley KH, Cassiello-Robbins CF, Vittorio L, Sauer-Zavala S, Barlow DH. The association between nonsuicidal self-injury and the emotional disorders: A meta-analytic review. Clin Psychol Rev 2015;37:72-88.

11. Gratz KL, Tull MT. Exploring the relationship between posttraumatic stress disorder and deliberate self-harm: The moderating roles of borderline and avoidant personality disorders. Psychiatry Res 2012;199:19-23.

12. Gradus JL, Leatherman S, Raju S, Ferguson R, Miller M. Posttraumatic stress disorder, depression, and non-fatal intentional self-harm in Massachusetts Veterans. Inj Epidemiol 2014;1:20.

13. Klonsky ED, Oltmanns TF, Turkheimer E. Deliberate self-harm in a nonclinical population: Prevalence and psychological correlates. Am J Psychiatry 2003;160:1501-8.

14. Maloney E, Degenhardt L, Darke S, Nelson EC. Investigating the cooccurrence of self-mutilation and suicide attempts among opioiddependent individuals. Suicide Life Threat Behav 2010;40:50-62.

15. Klonsky ED, Moyer A. Childhood sexual abuse and non-suicidal selfinjury: meta-analysis. Br J Psychiatry 2008;192:166-70.

16. Kinyanda $E$, Hjelmeland $H$, Musisi $S$. Negative life events associated with deliberate self-harm in an African population in Uganda. Crisis 2005;26:4-11.

17. Sleuwaegen E, Houben M, Claes L, Berens A, Sabbe B. The relationship between non-suicidal self-injury and alexithymia in borderline personality disorder: "Actions instead of words". Compr Psychiatry 2017;77:80-8.

18. Forrester RL, Slater H, Jomar K, Mitzman S, Taylor PJ. Self-esteem and non-suicidal self-injury in adulthood: A systematic review. J Affect Disord 2017;221:172-83.

19. Krysinska K, Heller TS, De Leo D. Suicide and deliberate self-harm in personality disorders. Curr Opin Psychiatry 2006;19:95-101.

20. Kang SG, Lee YJ, Kim SJ, Lim W, Lee HJ, Park YM, Cho IH, Cho SJ, Hong JP. Weekend catch-up sleep is independently associated with suicide attempts and self-injury in Korean adolescents. Compr Psychiatry 2014;55:319-25.

21. Hysing M, Sivertsen B, Stormark KM, O'Connor RC. Sleep problems and self-harm in adolescence. Br J Psychiatry 2015;207:306-12.

22. Singareddy R, Krishnamurthy VB, Vgontzas AN, Fernandez-Mendoza J, Calhoun SL, Shaffer ML, Bixler EO. Subjective and objective sleep and self-harm behaviors in young children: a general population study. Psychiatry Res 2013;209:549-53.

23. Sansone RA, Edwards HC, Forbis JS. Sleep quality and self-harm behaviors among internal medicine outpatients. Psychiatry (Edgmont) 2010;7:12-3.

24. Davoodi I, Neisi A, Khazei H, Arshadi N, Zakiei A. The roles of some cognitive and emotional factors in predicting insomnia. J Mazandaran Univ Med Sci 2017;27:107-21.

25. Bastien $\mathrm{CH}$, Vallières $\mathrm{A}$, Morin $\mathrm{CM}$. Validation of the Insomnia Severity Index as an outcome measure for insomnia research. Sleep Med 2001;2:297-307.

26. Netzer NC, Stoohs RA, Netzer CM, Clark K, Strohl KP. Using the Berlin Questionnaire to identify patients at risk for the sleep apnea syndrome. Ann Intern Med 1999;131:485-91.

27. Senaratna CV, Perret JL, Matheson MC, Lodge CJ, Lowe AJ, Cassim R, Russell MA, Burgess JA, Hamilton GS, Dharmage SC. Validity of the Berlin questionnaire in detecting obstructive sleep apnea: a systematic review and meta-analysis. Sleep Med Rev 2017;36:116-24.

28. Klonsky ED, Glenn CR. Assessing the functions of non-suicidal selfinjury: Psychometric properties of the Inventory of Statements About Self-injury (ISAS). J Psychopathol Behav Assess 2009;31:215-9.

29. Ennis CR, Short NA, Moltisanti AJ, Smith CE, Joiner TE, Taylor J. Nightmares and nonsuicidal self-injury: The mediating role of emotional dysregulation. Compr Psychiatry 2017;76:104-12.

30. Liu X, Chen H, Bo QG, Fan F, Jia CX. Poor sleep quality and nightmares are associated with non-suicidal self-injury in adolescents. Eur Child Adolesc Psychiatry 2017;26:271-9.

31. Lundh LG, Bjärehed J, Wångby-Lundh M. Poor sleep as a risk factor for nonsuicidal self-injury in adolescent girls. J Psychopathol Behav Assess 2013;35:85-92.

32. Demirci E. Non suicidal self-injury, emotional eating and insomnia after child sexual abuse: Are those symptoms related to emotion regulation? J Forensic Leg Med 2018;53:17-21.

33. Klonsky ED. The functions of deliberate self-injury: A review of the evidence. Clin Psychol Rev 2007;27:226-39. 